Article

\title{
Super-Twisting Differentiator-Based High Order Sliding Mode Voltage Control Design for DC-DC Buck Converters
}

\author{
Yigeng Huangfu ${ }^{1}$, Shengrong Zhuo ${ }^{1, *}$, Akshay Kumar Rathore ${ }^{2}$, Elena Breaz ${ }^{3,4}$, \\ Babak Nahid-Mobarakeh ${ }^{5}$ and Fei Gao ${ }^{3}$ \\ 1 School of Automation, Northwestern Polytechnical University, Xi'an 710072, China; yigeng@nwpu.edu.cn \\ 2 Department of Electrical and Computer Engineering, Concordia University, Montreal, \\ QC H3G 1M8, Canada; arathore@encs.concordia.ca \\ 3 Research Institute of Transport, Energy and Society (IRTES), University of Technology of \\ Belfort-Montbeliard, Belfort Cedex 90010, France; elena.breaz@utbm.fr (E.B.); fei.gao@utbm.fr (F.G.) \\ 4 Electrical Engineering Department, Technical University of Cluj-Napoca, Cluj-Napoca 400604, Romania \\ 5 Research Group in Electrical and Electronics, Université de Lorraine, Vandoeuvre-les-Nancy 54518, France; \\ babak.nahidmobarakeh@univ-lorraine.fr \\ * Correspondence: srzhuo@163.com; Tel.: +86-29-8843-1329
}

Academic Editor: Gabriele Grandi

Received: 25 April 2016; Accepted: 23 June 2016; Published: 28 June 2016

\begin{abstract}
This paper aims to focus on the smooth output of DC-DC buck converters in wireless power transfer systems under input perturbations and load disturbances using the high-order sliding mode controller (HOSM) and HOSM with super-twisting differentiator (HOSM + STD). The proposed control approach needs only measurement of converter output voltage. Theoretical analysis and design procedures, as well as the super-twisting differentiator of the proposed controller are presented in detail with the prescribed convergence law of high-order sliding modes. Comparisons of both simulation and experimental results among conventional proportional-integral (PI) control, traditional sliding mode control (SMC), HOSM and HOSM + STD under various test conditions such as steady state, input voltage perturbations and output load disturbances, are presented and discussed. The results demonstrate and validate the effectiveness and robustness of the proposed control method.
\end{abstract}

Keywords: robust control; DC-DC converter; sensor-less; high-order sliding mode

\section{Introduction}

Wireless power transfer has become a research focus during the last decade, due to its safety and convenience [1,2]. Its applications range from mobile phones [3], and electric vehicles [4] to electrical equipment in medical and other hazardous fields [5]. According to the experimental results in [6,7], the receiver output voltage varies with the distance, lateral misalignments and angular misalignments between the transmitter and the receiver. Therefore, in order to better power the load, a DC-DC converter is often added to regulate the receiver output voltage [8,9]. Due to the uncertainties of power source and load demand in such applications, the DC-DC converters always face the problem of maintaining a smooth output voltage under the circumstances of input voltage perturbations and load disturbances. It has been demonstrated in the literature that traditional linear controllers cannot cope with this problem appropriately. Thus, advanced nonlinear control methods need to be adopted. The sliding mode controller (SMC) is a kind of nonlinear controller which was firstly used in variable structure systems [10]. The major advantages of SMC are the guaranteed stability and the insensitivity to bounded matched disturbances, including modeling imperfections and/or external disturbances. 
In the field of power electronics, the switching characterization of DC-DC converters can be well described as variable structure systems $[11,12]$. Thus, it is naturally suitable to use the sliding mode algorithm to control the DC-DC converter under disturbances.

Over the past decade a large amount of literature has presented relevant research works on DC-DC converter controllers using the sliding mode algorithm [13-24]. The results have confirmed the strong robustness of the sliding mode control over the traditional linear PI control. In [13-15], the authors have presented the practical analog implementation of SMC in the basic DC-DC converters (including buck, boost and buck-boost converters) and had proposed some simple and easy-to-follow design procedures. An improved SMC has been reported in [16] by eliminating the reaching phase compared with the standard SMC, which enhances the insensibility of the studied boost converter system. Moreover, comparison between PI control and SMC based on the Cuk converter has shown again the latter's superior output performance [17]. However, the conventional sliding mode control has two problems that cannot be ignored when applying to DC-DC converter control. The first problem is that in order to achieve an optimized control performance using SMC, the system relative degree [25] with respect to the sliding variable should be equal to one (the first time derivative of sliding variable explicitly depends on the control $u$ ). For buck power converters, this condition can only be satisfied when the converter inductor current is chosen as the sliding control variable. In this case, the robustness of control under load disturbances cannot be guaranteed. The second problem is related to the so-called chattering effect in sliding mode control, which is difficult to be avoid or attenuated. The chattering effect will results in undesired output voltage ripple of the DC-DC converters.

The two intrinsic constrains of conventional SMC can be mitigated by using high-order sliding mode (HOSM) controllers through transferring the chattering into the high order sliding surface [26], while preserving the same control robustness. Control of DC-DC converters using super-twisting second order sliding mode has been studied in $[27,28]$. However, among the available literature, systematic and detailed design procedure of HOSM controllers (second-order or higher) applied to DC-DC converters is still an open problem. In this paper, prescribed convergence law (PCL) [29,30], which is one of the second-order sliding modes, is chosen and used to control a DC-DC buck converter.

To the best knowledge of the authors, the sliding mode controlled DC-DC buck converter generally needs to measure the capacitor current and the converter output voltage simultaneously [31,32]. In DC-DC power converter topologies, the output capacitor current is related directly to the time derivative of converter output voltage. If the output voltage is chosen to be the sliding variable in HOSM, the derivation of the voltage can thus be observed by a differentiator [33-38]. Therefore, the capacitor current sensor is no longer needed and can be removed from the control loop, further reduces the hardware cost of the system and provides more advantages compared to traditional PI control. In order to acquire a good output performance of the DC-DC converter, the differentiator should be as accurate as possible. It is inevitable that the input of the differentiator includes some small measurement noise. Thus the differentiator has also to be designed to be robust to the input noise. Super-twisting control, one of the second-order sliding mode algorithms, is suitable for estimating the derivative of the sliding variable.

The main objective of this paper is to propose an innovative controller design to ensure smooth voltage output of a DC-DC buck power converter under the input perturbations and load disturbances. The proposed control design uses a high-order sliding mode controller with a robust differentiator $($ HOSM + STD), and is based only on the measurement of converter output voltage. This paper is a major extension of the work presented in [39]. The main contributions of this paper can be summarized as follows:

- A robust HOSM controller based on PCL is designed for DC-DC buck converters, the corresponding systematic and detailed design procedure is presented in detail through theoretical analysis and simulation studies.

- By adding a super-twisting differentiator (STD) into the controller design, the current sensor is no longer needed for the converter control. The proposed HOSM + STD controller only uses the 
measurement of output voltage as control input. Thus the control system is simplified and the robustness of HOSM can also be preserved.

The paper is organized as follows: Sections 2 and 3 introduce the super-twisting differentiator and high order sliding mode controller for buck converters, respectively. Numerical simulations under various conditions have been presented in Section 4. The experimental results in Section 5 demonstrate the validity and the effectiveness of the proposed HOSM and HOSM + STD controllers. Finally, conclusions are given in Section 6.

\section{Super-Twisting Differentiator Design}

\subsection{DC-DC Buck Power Converter Model}

To control efficiently the buck converter using advanced nonlinear control methods, it is necessary to build firstly the mathematical converter model using the state space equation. Figure 1 shows the basic topology of the buck converter, where $S$ is the switch, $D$ is the diode. $L, C$, and $R$ are the inductance, capacitor and load resistance, respectively. $V_{\text {in }}$ is the input DC voltage, and $V_{\mathrm{o}}$ is the output voltage. $i_{\mathrm{L}}, i_{\mathrm{C}}$ and $i_{\mathrm{O}}$ are the current flowing through the inductor, capacitor and load resistance, respectively. Note that the gate driving signal for MOSFET is denoted by $u$ and its frequency is variable and determined by the SMC or HOSM control algorithm. The average system model for DC-DC buck converter can thus be written as follows:

$$
\left[\begin{array}{c}
\frac{d i_{L}}{d t} \\
\frac{d v_{0}}{d t}
\end{array}\right]=\left[\begin{array}{cc}
0 & -\frac{1}{L} \\
\frac{1}{C} & -\frac{1}{R C}
\end{array}\right]\left[\begin{array}{c}
i_{L} \\
v_{0}
\end{array}\right]+\left[\begin{array}{c}
\frac{v_{i n}}{L} \\
0
\end{array}\right] u
$$

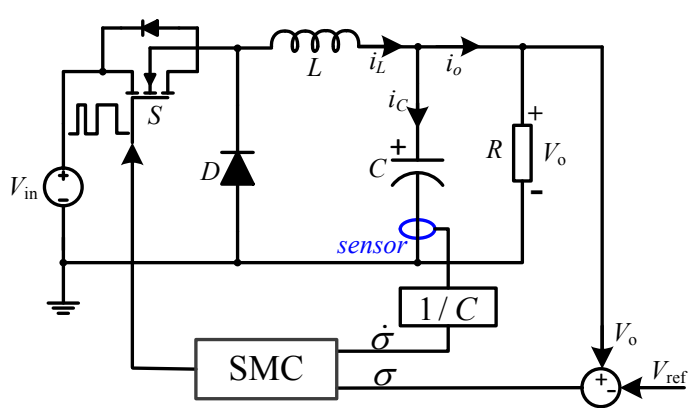

(a)

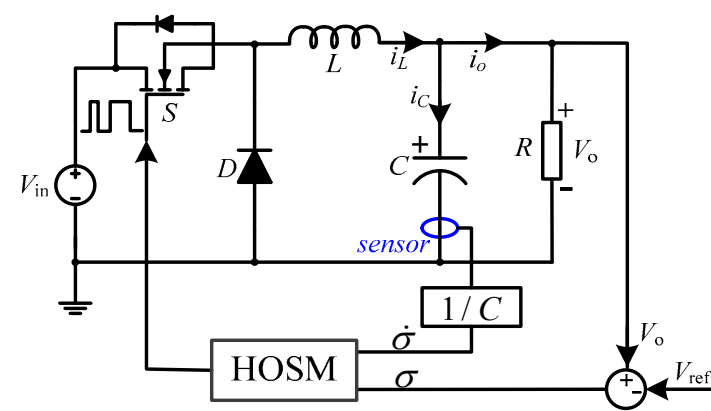

(b)

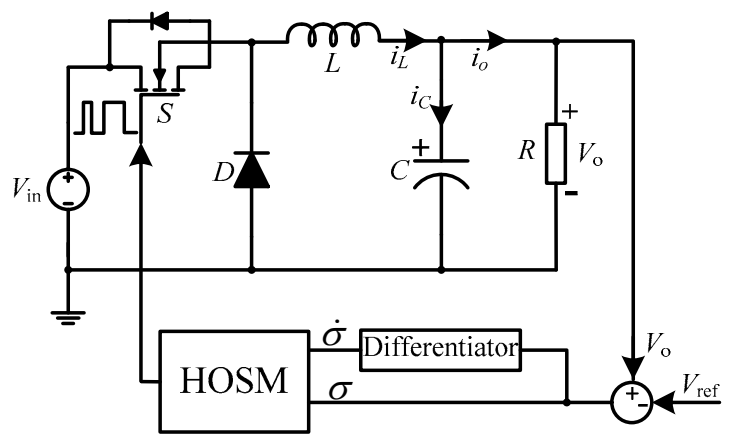

(c)

Figure 1. Basic structure of a buck converter: (a) SMC with measurements of both capacitor current and output voltage; (b) HOSM with measurements of both capacitor current and output voltage; (c) HOSM + STD (differentiator) with the only measurement of output voltage. 
Let $x_{1}=v_{o}-V_{r e f}$, then the model (1) can be rewritten as:

$$
\dot{x}_{1}=x_{2}=\frac{1}{C}\left(i_{L}-\frac{v_{o}}{R}\right), \dot{x}_{2}=\frac{v_{i n}}{L C} u+\left(-\frac{1}{L C} v_{o}-\frac{1}{R C}\left(i_{L}-i_{o}\right)\right)
$$

and in its state-space form:

$$
\left[\begin{array}{l}
\dot{x}_{1} \\
\dot{x}_{2}
\end{array}\right]=\left[\begin{array}{cc}
0 & 1 \\
-\frac{1}{L C} & -\frac{1}{R C}
\end{array}\right]\left[\begin{array}{l}
x_{1} \\
x_{2}
\end{array}\right]+\left[\begin{array}{c}
0 \\
\frac{v_{i n}}{L C}
\end{array}\right] u+\left[\begin{array}{c}
0 \\
-\frac{V_{r e f}}{L C}
\end{array}\right]
$$

\subsection{Differentiator Design Based on Super-Twisting Algorithm}

In this paper, the Super-Twisting Algorithm (STA) is proposed to build the voltage Super-Twisting Differentiator (STD) in the controller. The STA can be described as [25]:

$$
\begin{aligned}
& u=-\lambda_{1}|x|^{1 / 2} \operatorname{sign}(x)+u_{1} \\
& \dot{u}_{1}=-\lambda_{0} \operatorname{sign}(x)
\end{aligned}
$$

without loss generality for a linear system:

$$
\dot{x}=a(t, x)+b(t, x) u
$$

where $x$ is the state variable, $a$ and $b$ are smooth unknown functions, the superscript $(\cdot)$ stands for the first derivative, $u$ is the control law, $u_{1}$ is the intermediate variable, $t$ is the time, sign is the common sign function, constants $\lambda_{0}$ and $\lambda_{1}$ are tuned to ensure finite time convergence to the second order sliding mode set $x(t)=\dot{x}(t)=0, \forall t \geqslant T$ without using $\dot{x}$.

The derivational process of STD based on STA is briefly presented here, and the detail proof can be found in [34]. Denote $f(\mathrm{t})$ be a signal to be differentiated and its second derivative satisfy $|\ddot{f}(t)| \leqslant L_{c}$, $L_{c}$ is a known Lipschitz constant. Consider an auxiliary system $\dot{z}_{0}=v$, where $z_{0}$ is the state variable, $v$ is the control input. Define the sliding variable $\sigma_{0}=z_{0}-f(t)$, it follows from Equations (4) and (5) that $\forall t \geqslant T$.

$$
\sigma_{0}=z_{0}-f(t)=0, \dot{\sigma}_{0}=\dot{z}_{0}-\dot{f}(t)=0
$$

after STA is well designed and applied to the auxiliary system. Thus the auxiliary system and the control input can be reformulated as:

$$
\begin{aligned}
& \dot{\sigma}_{0}=-\dot{f}(t)+v \\
& \dot{z}_{0}=v=-\lambda_{1}\left|\sigma_{0}\right|^{1 / 2} \operatorname{sign}\left(\sigma_{0}\right)+z_{1}, \dot{z}_{1}=-\lambda_{0} \operatorname{sign}\left(\sigma_{0}\right)
\end{aligned}
$$

According to Equations (6) and (7), the required differentiator for $f(t)$ is established:

$$
\begin{aligned}
& \dot{f}(t)=\dot{z}_{0}=v=-\lambda_{1}\left|z_{0}-f(t)\right|^{1 / 2} \operatorname{sign}\left(z_{0}-f(t)\right)+z_{1} \\
& \dot{z}_{1}=-\lambda_{0} \operatorname{sign}\left(z_{0}-f(t)\right)
\end{aligned}
$$

For digital processor implementation, the discrete version of STD can be formulated as follows using the Euler method:

$$
\begin{aligned}
& z_{0}(k+1)=z_{0}(k)+T_{s} z_{1}(k)-T_{s} \lambda_{1}\left|z_{0}(k)-f(k)\right|^{\frac{1}{2}} \operatorname{sign}\left(z_{0}(k)-f(k)\right) \\
& z_{1}(k+1)=z_{1}(k)-T_{s} \lambda_{0} \operatorname{sign}\left(z_{0}(k)-f(k)\right)
\end{aligned}
$$

where $T_{\mathrm{S}}$ is the sample period, $k=0,1,2, \ldots$ 


\subsection{Gains of the STD}

The convergence condition for continuous and discrete STD are thoroughly discussed in $[34,35]$. It has been indicated that, if the constants $\lambda_{0}$ and $\lambda_{1}$ satisfy Equation (10) and $f(t)$ is noise free, then $z_{0}$ and $\dot{z}_{0}$ converge in finite time to $f(t)$ and $\dot{f}(t)$, respectively:

$$
\lambda_{0}>L_{c}, \lambda_{1}^{2} \geqslant 4 L_{c} \frac{\lambda_{0}+L_{c}}{\lambda_{0}-L_{c}}
$$

In practice, one way to choose $\lambda_{0}$ and $\lambda_{1}$ is to take:

$$
\lambda_{0}=\mu_{0} L_{c}, \lambda_{1}=\mu_{1} \sqrt{L_{c}}
$$

with proper chosen values of $\mu_{0}$ and $\mu_{1}$. In particular, $\mu_{0}=1.1, \mu_{1}=1.5$ is a valid choice [34].

From the condition $|\ddot{f}(t)| \leqslant L_{c}$ and Equation (3), it can be derived that:

$$
|\ddot{f}|<\frac{1}{C}\left(\left|\frac{1}{L}\left(v_{\text {in }} u-V_{o}\right)\right|+\left|\frac{1}{R C} i_{c}\right|\right)=L_{c}
$$

It is worth to indicate that, finite time convergence conditions of the differentiator allows to design the controller and differentiator separately [40].

\section{Sliding Mode Controller Design}

Consider a general linear system with relative degree two in state-space form [30]:

$$
\dot{x}=a(t, x)+b(t, x) u
$$

$x \in \Re^{2}$, with the sliding variable:

$$
\sigma=x_{1}
$$

where $x=\left[x_{1}, x_{2}\right]^{T}$ is the state variable matrix, $a, b, \sigma$ are smooth unknown functions. Calculation of the second derivative of $\sigma$ and yields:

$$
\ddot{\sigma}=h(t, x)+g(t, x) u, h=\left.\ddot{\sigma}\right|_{u=0}, g=\frac{\partial}{\partial u} \ddot{\sigma} \neq 0
$$

where $h(t, x)$ and $g(t, x)$ are unknown functions. Assume that:

$$
0<K_{m} \leqslant g \leqslant K_{M},|h| \leqslant H
$$

holds globally for $K_{\mathrm{m}}, K_{\mathrm{M}}, H>0$. Then Equations (15) and (16) imply the differential inclusion:

$$
\ddot{\sigma} \in[-H, H]+\left[K_{m}, K_{M}\right] u
$$

Thus the problem becomes to find a robust control law:

$$
u=\varphi(\sigma, \dot{\sigma})
$$

such that $\sigma$ and $\dot{\sigma}$ could approach to zero exponentially or in finite time. 


\subsection{Traditional Sliding Mode Control}

The sliding mode control design process can be divided into two parts: the first part is to define a switching manifold $S(x)$ which describe the desirable dynamic properties. The second part is to then define a discontinuous control law $u$ :

$$
u=\left\{\begin{array}{l}
u^{+} S(x)>0 \\
u^{-} S(x)<0
\end{array}\right.
$$

such that:

$$
\lim _{s \rightarrow 0^{+}} \dot{S}<0, \lim _{S \rightarrow 0^{-}} \dot{S}>0
$$

In [13], $S=k \sigma+\dot{\sigma}\left(\sigma=v_{o}-V_{r e f}\right)$ is chosen as the sliding surface, and the corresponding control law for DC-DC buck converter was designed as:

$$
u=\frac{1}{2}(1-\operatorname{sign}(S))
$$

The positive parameter $k$ recommended by [13] is:

$$
k=\frac{1}{R C}
$$

by taking into account the maximum existence region based on the existence condition [13]. Wherein $R$ is the load resistance and $C$ is the capacitance of the buck converter.

The sliding mode control process can be distinguished into sliding mode phase and reaching phase. During the sliding mode phase, there exists:

$$
S=k \sigma+\dot{\sigma}=0, k>0
$$

Therefore:

$$
\begin{gathered}
\sigma=x_{1}=x_{1}(0) \exp (-k t) \\
\dot{\sigma}=x_{2}=-k x_{1}(0) \exp (-k t)
\end{gathered}
$$

It is clear that $x_{1}$ and $x_{2}$ approach to zero exponentially under traditional sliding mode control. Moreover, the proportional-derivative (PD) type feedback in traditional sliding mode control Equation (23) will cause a nonzero steady state error in the DC-DC buck converter output voltage [41]. Indeed, the nonzero steady state error can be attenuated by adding an integral term and a double integral term of all other existing state variables in sliding mode surface [42]. However, this will increase the number of controller parameters and finally increase the design complexity. The drawback of nonzero steady state error is significantly improved by the following proposed controllers without adding the number of design parameters.

\subsection{Second Order Sliding Mode Control}

As described previously, a DC-DC buck converter is a system with relative degree of two. Thus it might be more suitable to use the second order sliding mode controller to improve the control accuracy and convergence time. The Prescribed Convergence Law (PCL), which is a type of second order sliding mode control, is defined as $[29,30]$ :

$$
u=-\alpha \operatorname{sign}\left(\dot{\sigma}+\beta|\sigma|^{1 / 2} \operatorname{sign} \sigma\right)
$$

where $\alpha>0, \beta>0$. 
It has been demonstrated in [30] that the controller can guarantee the establishment and maintenance of a second-order sliding mode $\sigma \equiv 0$ for the sliding variable dynamics Equation (17) in finite time, if the following precondition could be satisfied:

$$
\alpha K_{m}-H>\beta^{2} / 2
$$

For the DC-DC buck converter application, the control signal for the power switch belongs to $\{0,1\}$. When $u=1$, the power switch is on, and when $u=0$, the power switch is off. Therefore, be similar to Equations (21), (25) and (26) can be reformulated as:

$$
\begin{gathered}
u=\frac{1}{2}\left(1-\operatorname{sign}\left(\dot{\sigma}+\beta|\sigma|^{1 / 2} \operatorname{sign} \sigma\right)\right) \\
K_{m}-H>\beta^{2} / 2
\end{gathered}
$$

According to Equations (3) and (14)-(16), the $K_{m}$ and $H$ can be formulated as:

$$
\begin{gathered}
K_{m}=\min \left(\frac{1}{L C} V_{i}\right) \\
H=\frac{1}{C}\left(\frac{1}{L} V_{o}+\frac{1}{R} i_{c}\right)
\end{gathered}
$$

Thus, in the proposed controller design, the only design parameter is $\beta$, which must satisfy Equation (28). It has to be noted that, Equation (28) ensures the finite time convergence of $\sigma \rightarrow 0$ with the second order sliding mode control PCL. Thus the bigger the value of $\beta$, the faster the convergence.

As a result, the proposed High-Order Sliding Mode (HOSM) controller with Super-Twisting Differentiator (STD) for DC-DC buck converter can thus be expressed as:

$$
u=\left(1-\operatorname{sign}\left(\dot{z}_{0}+\beta|\sigma|^{1 / 2} \operatorname{sign} \sigma\right)\right) / 2
$$

where $\dot{z}_{0}$ is the estimation of $\dot{\sigma}$ based on STD in Equation (8).

\section{Simulation Results}

To verify the effectiveness and robustness of the proposed innovative control method in this paper, three simulation models (SMC, HOSM, HOSM + STD) were established in Matlab/Simulink based on diagrams shown in Figure 1. For the simulation diagrams of Figure 1a,b, both output voltage and capacitor current are measured and treated as the inputs of the controller for the buck converter. While for simulation diagram of Figure 1c, the error between the measured output voltage and the reference voltage is treated as the input of the differentiator and the sliding mode controller. There is no capacitor current measurement in Figure 1c.

The design index and circuit parameter are listed in Table 1. Substitute the data into Equations (11), (12), (22) and (28)-(30), both the differentiator and the controller can then be designed. The calculated parameter of $\lambda_{0}, \lambda_{1}, k$ and $\beta$ are summarized in Table 2 .

Table 1. Design index and circuit parameters.

\begin{tabular}{cc}
\hline Item & Value \\
\hline Input Voltage, $V_{\text {in }}$ & $8-15 \mathrm{~V}$ \\
Reference Voltage, $V_{\text {ref }}$ & $5 \mathrm{~V}$ \\
Inductance, $L$ & $2 \mathrm{mH}$ \\
Capacitance, $C$ & $4700 \mu \mathrm{F}$ \\
Load Resistance, $R$ & $2.5-10 \Omega$ \\
\hline
\end{tabular}


Table 2. The controller parameters.

\begin{tabular}{cc}
\hline Parameter & Value \\
\hline$\lambda_{0}$ & $2 \times 10^{6}$ \\
$\lambda_{1}$ & $2 \times 10^{3}$ \\
$k$ & 85 \\
$\beta$ & 70.2 \\
\hline
\end{tabular}

For each presented control diagram, numerical simulation results (carried out using the Euler solver with a time step $10 \mu \mathrm{s}$ ) under steady state, input voltage perturbations and output load disturbances have been compared and presented hereafter.

\subsection{Controller Performance with Different Design Parameters}

Under the nominal working condition, the input voltage is set to $15 \mathrm{~V}$, and the load resistance is set to $2.5 \Omega$. The output voltage and the corresponding inductor current curves of a buck converter under different controllers with various controller parameters are pictured in Figure 2.

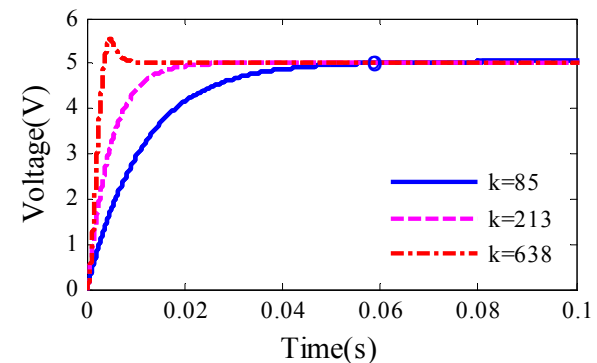

(a)

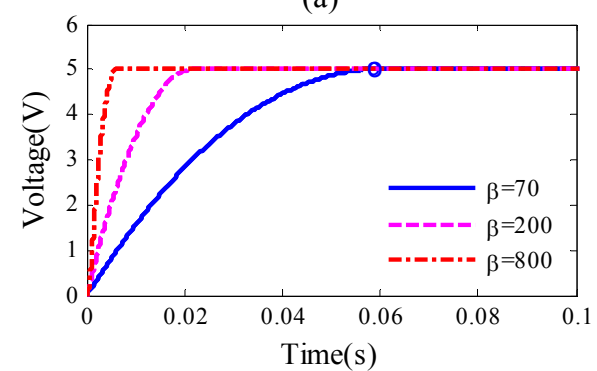

(c)

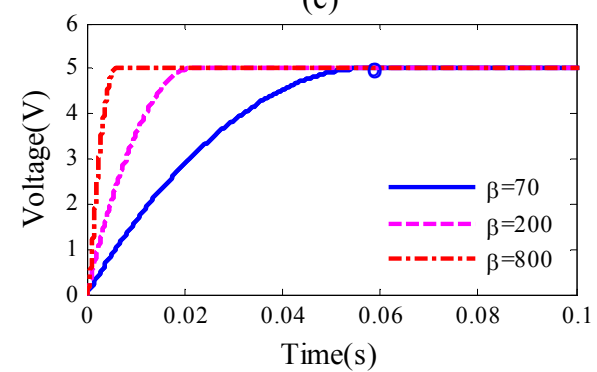

(e)

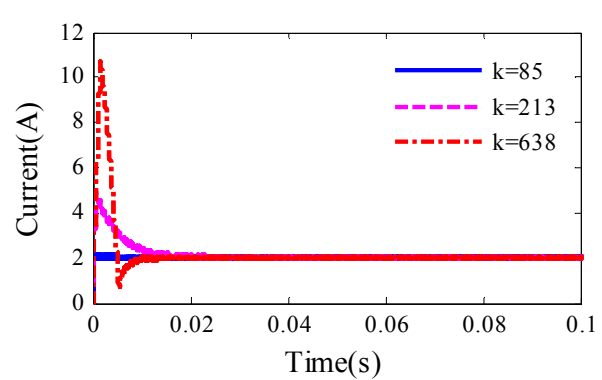

(b)

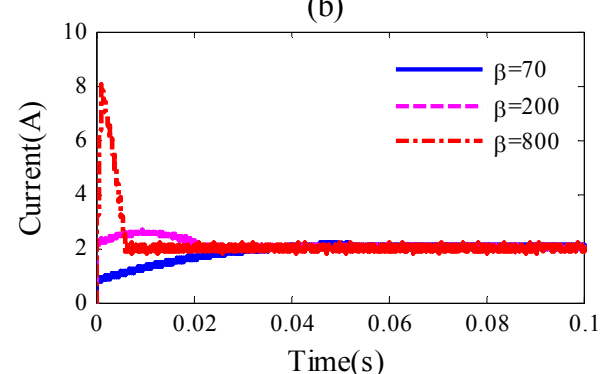

(d)

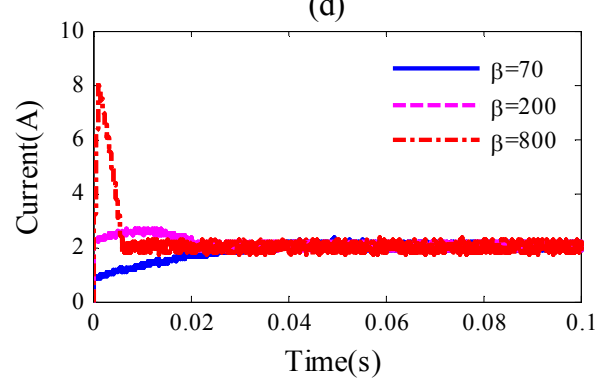

(f)

Figure 2. Simulation results of the output voltage and the inductor current curve varies with controller parameters. (a) Output voltage of SMC; (b) Inductor current of SMC; (c) Output voltage of HOSM; (d) Inductor current of HOSM; (e) Output voltage of HOSM + STD; (f) Inductor current of HOSM + STD.

It can be seen clearly from the figure that, a bigger value of controller design parameters $k$ and $\beta$ can lead to a faster response of the output voltage, but if the value of $k$ or $\beta$ becomes too large, voltage overshoot might occur for both output voltage and inductor current, as shown in Figure 2a,b. The current overshoot phenomenon is however inevitable for HOSM, as presented in Figure $2 c, d$. 
Therefore, when tuning the value of $k$ and $\beta$, the output voltage convergence speed and the possible current overshoot should both be considered and a balance need to be found. The peak inductor current can be calculated as follows:

Take Figure $2 \mathrm{~b}$ as an example of SMC, suppose that the Equation (23) is established sooner after the start up, there exists:

$$
\dot{\sigma}=k \sigma
$$

The inductor current can be formulated as:

$$
i_{L}=i_{o}+i_{c}=\frac{v_{o}}{R}+C \dot{\sigma}
$$

Furthermore:

$$
i_{L}=\frac{\sigma+V_{r e f}}{R}+C \dot{\sigma}=\frac{V_{r e f}}{R}+\left(\frac{1}{R}-k C\right) \sigma
$$

If the minimum inductor current overshoot is expected, the biggest $k$ can be set to $1 /(\mathrm{RC})$, which coincides with the results in Equation (22). If $k$ equals to 1/(RC), we would have:

$$
\max \left(i_{L}\right)=\frac{V_{r e f}}{R}=2 \mathrm{~A}
$$

This calculated values ( $2 \mathrm{~A}$ ) is identical to the simulation result plotted with blue solid line in Figure $2 b$, which demonstrate the effectiveness of Equation (33). Similar to the analysis of SMC, the peak inductor current of the buck converter controlled by HOSM can also be estimated. Take Figure $2 \mathrm{~d}$ as an example, without loss of generality, suppose that there exists:

$$
\dot{\sigma}+\beta|\sigma|^{1 / 2} \operatorname{sign} \sigma=0
$$

according to Equation (32), we can have:

$$
i_{L}=\frac{\sigma+V_{r e f}}{R}+C \dot{\sigma}=\frac{V_{r e f}}{R}+\left(\frac{1}{R}-k C\right) \sigma
$$

In order to test the effectiveness of Equation (34), we take red dot-dash line in Figure $2 \mathrm{~d}$ as an example: substitutes $\beta=800$ into Equation (34), one obtains:

$$
\max \left(i_{L}\right)=\frac{V_{r e f}}{R}-\frac{V_{r e f}}{R}-C \beta|\sigma|^{1 / 2} \operatorname{sign} \sigma=8.4 \mathrm{~A}
$$

This calculation result is coincide with the simulation results in Figure $2 \mathrm{~d}$. Then based on Equation (34), the critical value of $\beta$ about whether the current overshoot phenomenon occurs can be calculated as:

$$
\beta_{c}=\frac{\sqrt{V_{r e f}}}{R C}=190
$$

It should be kept in mind that Equations (33) and (34) can only provide an estimation of peak inductor current during the start-up process.

From Figure 2c,e, it can be seen that the HOSM + STD has similar convergence speed (see the small blue circle in Figure 2) as that of HOSM. From Figure 2d,f, it can be seen that HOSM + STD may cause a slightly bigger ripple in the inductor current. Otherwise, the STD cooperates with HOSM very well.

It should be noted that, in this paper, the $k$ is chosen according to Equation (22), while in order to let the rising time of SMC and HOSM be equal, the value of $\beta$ is selected properly as in Table 2 . Theoretically, the $\beta$ can be chosen up to 190 with the consideration of the inductor current overshoot 
avoidance. It implies also that the HOSM can achieve faster convergence than SMC under the same constrains of the current overshoot avoidance.

\subsection{Disturbance in Input Voltage}

In order to test the robustness of the proposed controller against the input voltage disturbance, a step change from 15 to $8 \mathrm{~V}$ at $0.25 \mathrm{~s}$ is applied to the buck converter input voltage. The simulation results are shown in Figure 3. Before to start the discussion about robustness of the controller, the steady state performance is analyzed at first, as given in Table 3. It can be seen that SMC and HOSM has the same rising time $57.5 \mathrm{~ms}$, but HOSM can achieve smaller steady state error than SMC. In Figure 3, it is shown that the proposed Super-Twisting Differentiator (STD) works well since the start-up and the steady state performance of HOSM + STD is similar to that of HOSM, except a slightly bigger output voltage ripple. The additional output voltage ripple is mainly caused by the fact that the estimated derivation is less smooth than the measured derivative, as shown in Figure 3c.

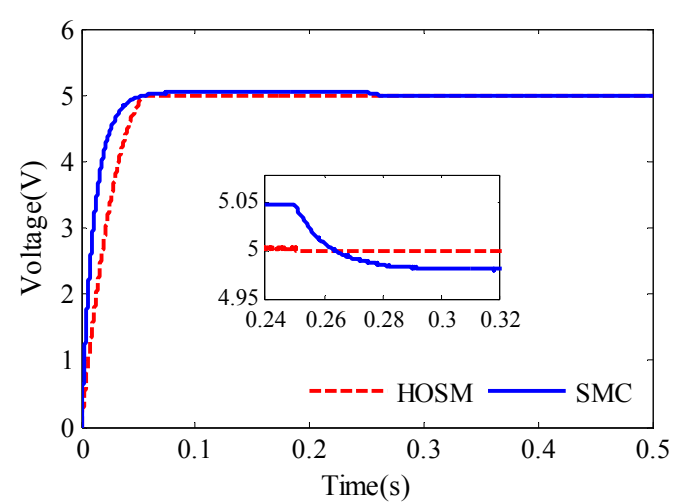

(a)

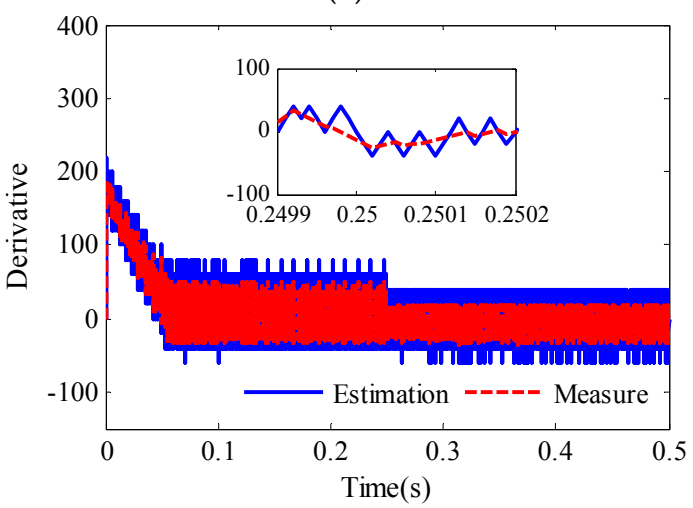

(c)

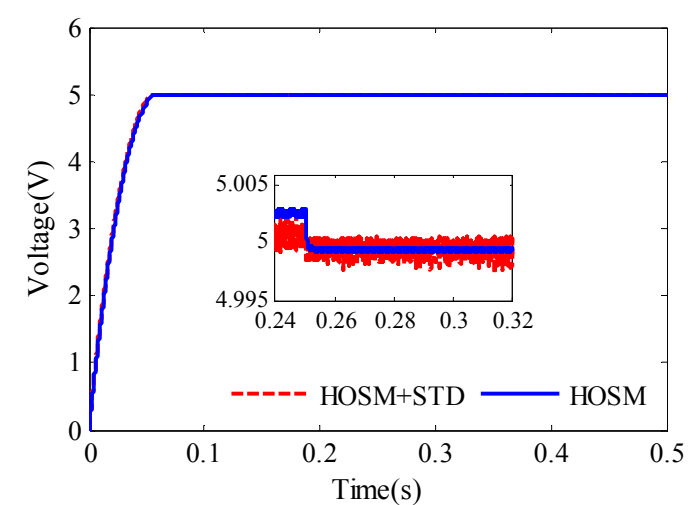

(b)

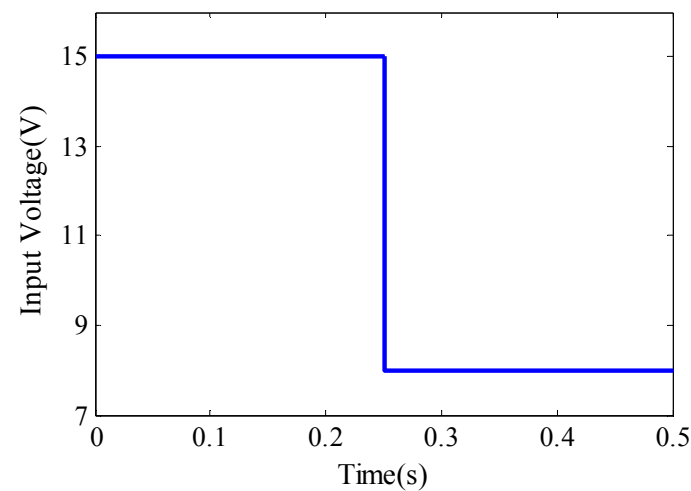

(d)

Figure 3. Simulation results for the buck converter under the perturbation in input voltage (step change from 15 to $8 \mathrm{~V}$ at $0.25 \mathrm{~s}$ ), $\beta=70.2, k=85$. (a) Output voltage comparison between HOSM and SMC; (b) Output voltage comparison between HOSM + STD and HOSM; (c) Comparison between the measured and estimated derivative of the sliding mode variable $\mathrm{d} \sigma / \mathrm{d} t ;(\mathbf{d})$ The input voltage.

Table 3. Steady state performance analysis results.

\begin{tabular}{ccc}
\hline \multirow{2}{*}{ Controller } & \multicolumn{2}{c}{ Output Voltage } \\
\cline { 2 - 3 } & Rising Time & Steady State Error \\
\hline SMC & $57.5 \mathrm{~ms}$ & $48.2 \mathrm{mV}, 0.96 \%$ \\
HOSM & $57.5 \mathrm{~ms}$ & $2.6 \mathrm{mV}, 0.05 \%$ \\
HOSM + STD & $54.9 \mathrm{~ms}$ & $0.7 \mathrm{mV}, 0.01 \%$ \\
\hline
\end{tabular}


From Figure 3, it can be concluded that, all these three controllers show robustness to the input voltage disturbance. The detailed analysis results are presented in Table 4 . The controlled output voltage drop of SMC is $67.9 \mathrm{mV}$, and needs $73.8 \mathrm{~ms}$ recovery time. While the voltage drop of HOSM controllers is $3.2 \mathrm{mV}$ and needs about $1.3 \mathrm{~ms}$ recovery time. The combination of HOSM + STD controller also shows strong robustness to the input voltage disturbance, the voltage drop of HOSM + STD is $1.4 \mathrm{mV}$ and needs about $0.1 \mathrm{~ms}$ recovery time.

Table 4. Input voltage perturbation analysis results.

\begin{tabular}{ccc}
\hline \multirow{2}{*}{ Controller } & \multicolumn{2}{c}{ Output Voltage } \\
\cline { 2 - 3 } & Voltage Drop & Recovery Time \\
\hline SMC & $67.9 \mathrm{mV}, 1.36 \%$ & $73.8 \mathrm{~ms}$ \\
HOSM & $3.2 \mathrm{mV}, 0.06 \%$ & $1.3 \mathrm{~ms}$ \\
HOSM + STD & $1.4 \mathrm{mV}, 0.03 \%$ & $0.1 \mathrm{~ms}$ \\
\hline
\end{tabular}

\subsection{Disturbance in Output Load Resistance}

In order to test the robustness of the proposed controller for the buck converter under load disturbance, the load is doubled at $0.25 \mathrm{~s}$. The corresponding simulation results are compared and pictured in Figure 4.

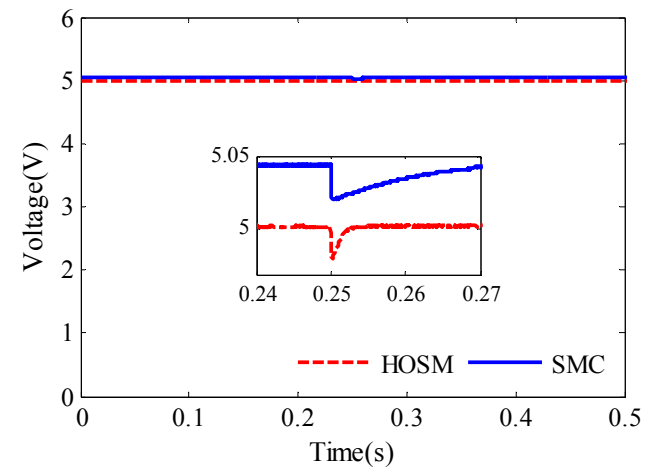

(a)

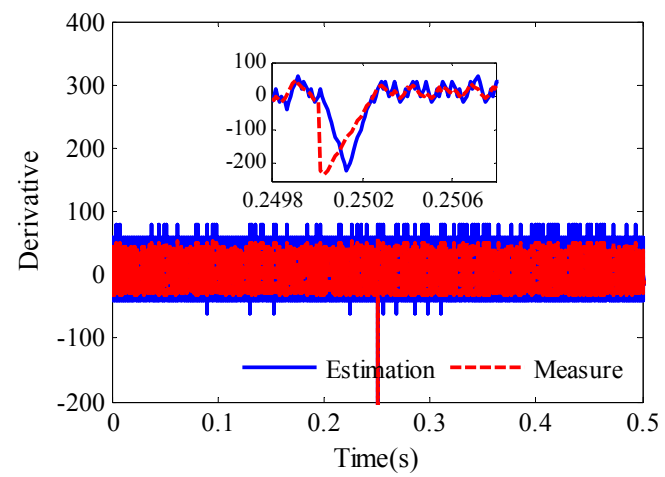

(c)

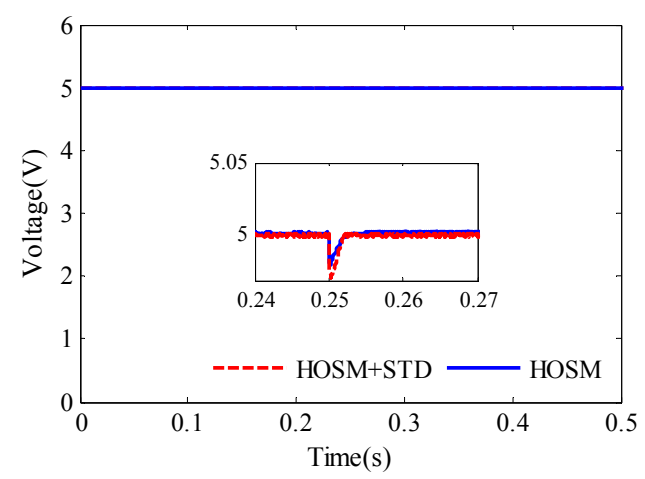

(b)

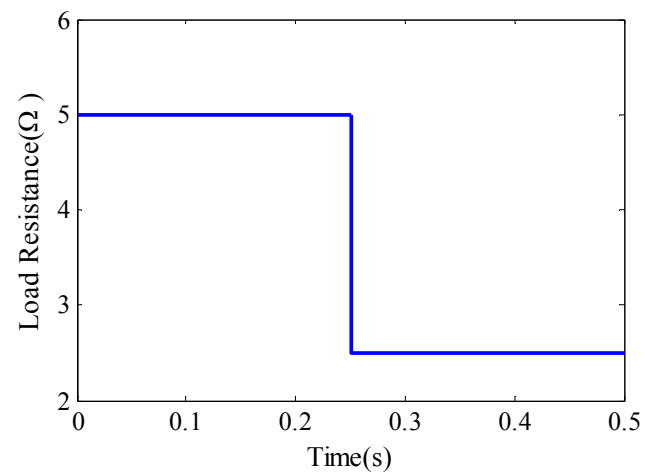

(d)

Figure 4. Simulation results for the buck converter under the disturbance in load resistance (step change from 5 to $2.5 \Omega$ at $0.25 \mathrm{~s}$ ), $\beta=70.2, k=85$. (a) Output voltage comparison between HOSM and SMC; (b) Output voltage comparison between HOSM + STD and HOSM; (c) Comparison between the measured and estimated derivative of the sliding mode variable $\mathrm{d} \sigma / \mathrm{d} t$; (d) The load resistance.

It can be concluded that all these three controllers show strong robustness to the load disturbance. The more detailed analysis results are listed in Table 5, where it can be seen that the transient voltage 
drop is similar for all controllers (about $25 \mathrm{mV}$ ), which is mainly determined by the buck converter circuits (inductor, capacitor) and load current. The recovery time of SMC is about $30.6 \mathrm{~ms}$, HOSM needs $5.1 \mathrm{~ms}$, and that of HOSM + STD is about $2.1 \mathrm{~ms}$. The results have demonstrate that the proposed HOSM + STD shows strong robustness to the load disturbance, according to Figure $4 \mathrm{~b}$. It can also be seen from Figure $4 \mathrm{~b}$ that, the proposed HOSM + STD has the similar dynamic performance as single HOSM controllers with additional current input.

Table 5. Output load disturbance analysis results.

\begin{tabular}{ccc}
\hline \multirow{2}{*}{ Controller } & \multicolumn{2}{c}{ Output Voltage } \\
\cline { 2 - 3 } & Transient Voltage Drop & Recovery Time \\
\hline SMC & $23.6 \mathrm{mV}, 0.47 \%$ & $30.6 \mathrm{~ms}$ \\
HOSM & $21.3 \mathrm{mV}, 0.43 \%$ & $5.1 \mathrm{~ms}$ \\
HOSM + STD & $29.2 \mathrm{mV}, 0.58 \%$ & $2.1 \mathrm{~ms}$ \\
\hline
\end{tabular}

\section{Experimental Results}

Furthermore, in order to valid experimentally the effectiveness of the proposed HOSM and HOSM + STD controllers, an experimental setup including a prototype DC-DC buck converter and a control board based on 32 bit-150 MHz TMS320F28335 (Digital Signal Processor from Texas Instruments, Dallas, TX, USA) had been established, as shown in Figure 5. The experimental circuit parameters are the same as shown in Table 1. In order to better evaluate the presented control method, the classical proportional-integral (PI) controller has been comparatively studied. The controller parameters of SMC, HOSM and HOSM + STD are chosen as $\lambda_{0}=2 \times 10^{6}, \lambda_{1}=2 \times 10^{3}, k=85, \beta=300$ in the following experiments. The PI controller parameters are tuned by combing bode diagram and cut-and-trial method, and finally set as $K p=0.7, K i=84$.
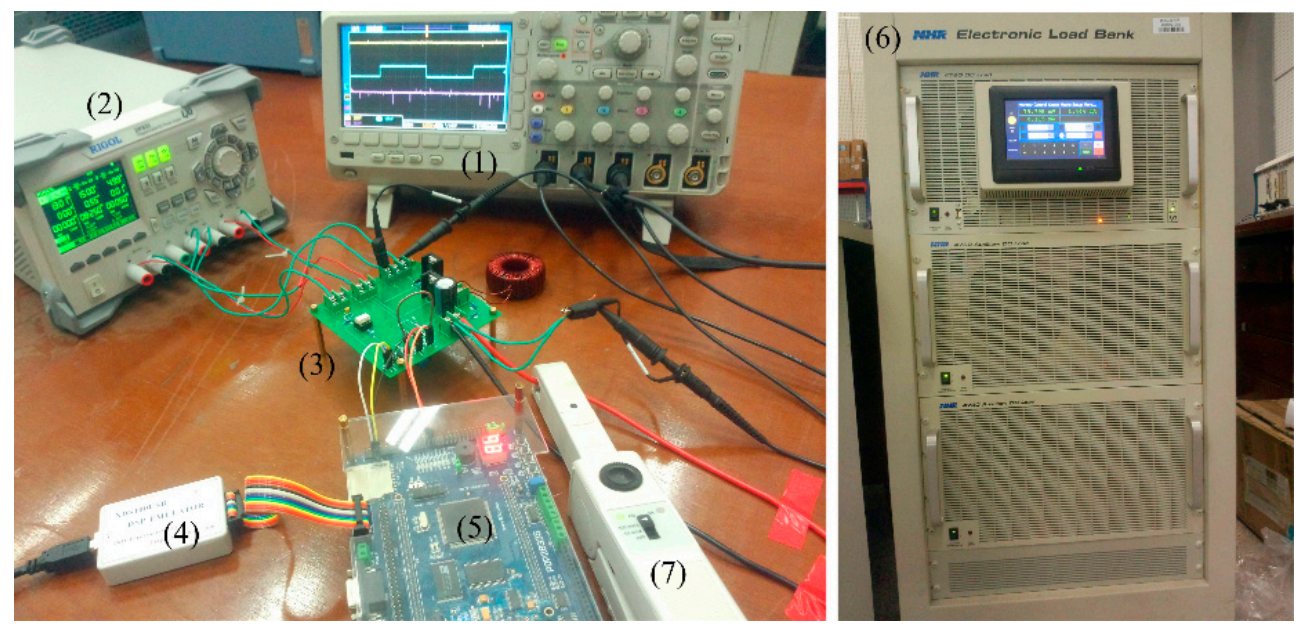

Figure 5. Experimental setup of DC-DC buck converter. (1) Oscilloscope; (2) Power supplies for the driver, current sensor and converter; (3) DC-DC buck converter; (4) Emulator; (5) DSP board; (6) Electronic load; (7) Current probe.

Figure $6 \mathrm{a}, \mathrm{b}$ shows the steady state performance of these four controllers (PI, SMC, HOSM and HOSM + STD). From Figure 6a, it can be concluded that PI, HOSM and HOSM + STD can achieve less steady state error and better voltage regulation than SMC. In particular, the HOSM + STD controller has the similar performance with HOSM, especially with low input voltage. Note that the experimental steady state error is larger than that of simulation results in Table 3. There could be many reasons for this observed difference, such as the measure and sampling imperfections, the discretization of the 
controller and the differentiator. From Figure 6b, it can be concluded that PI and HOSM have smaller steady state error and better load regulation than SMC during the whole load range. Particularly, the HOSM + STD controller still has the similar performance with HOSM.

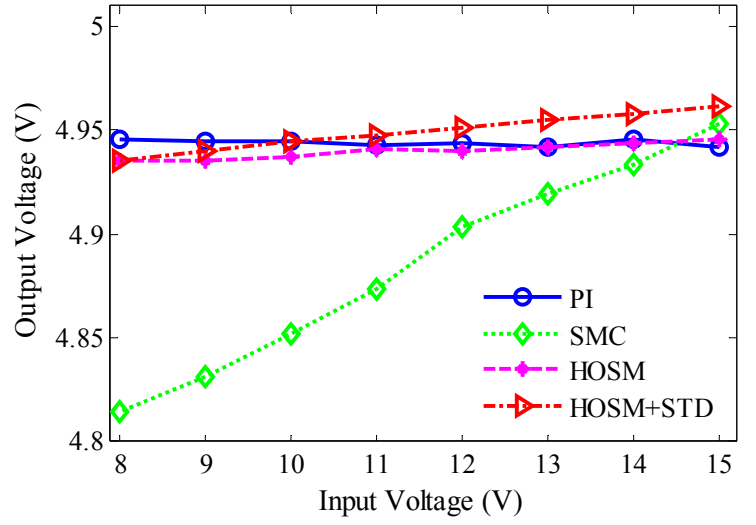

(a)

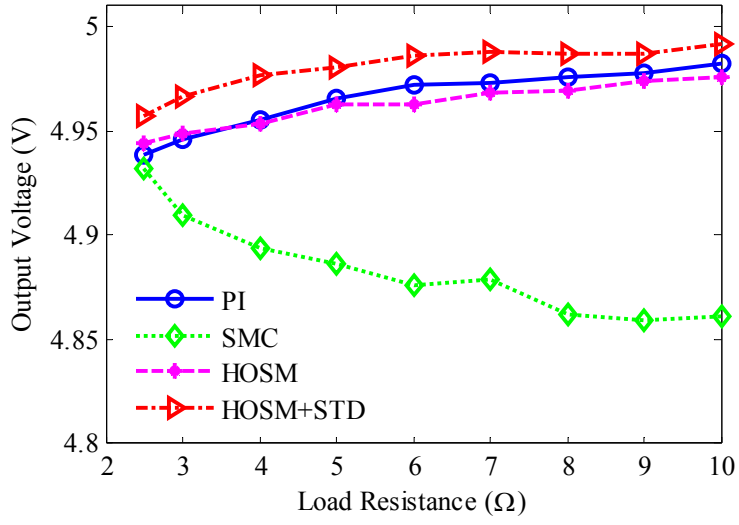

(b)

Figure 6. Experimental results of average output voltage (a) for different input voltage $(R=2.5 \Omega)$; (b) for different load resistance $\left(V_{\text {in }}=15 \mathrm{~V}\right)$.

In the second experimental test, to valid the robustness to the input voltage perturbations, step changes from 15 to $8 \mathrm{~V}$ and back to $15 \mathrm{~V}$ are applied to the buck converter with a constant $2.5 \Omega$ load. The experimental results are shown in Figure 7.

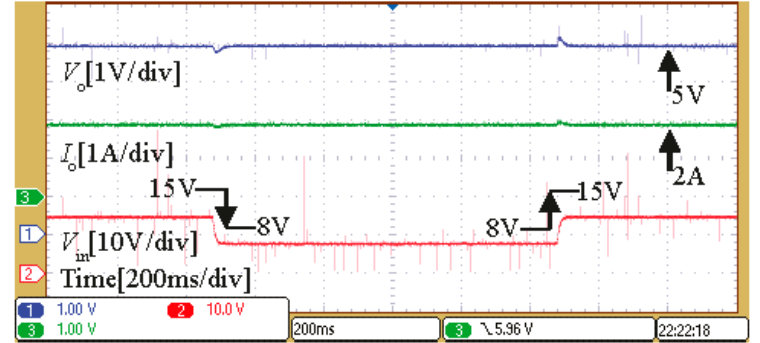

(a) PI

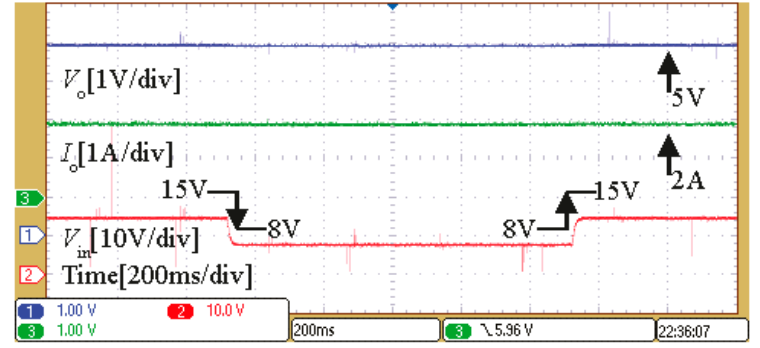

(c) HOSM

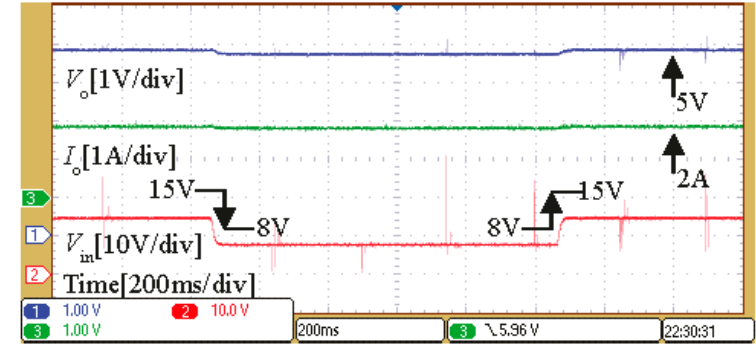

(b) SMC

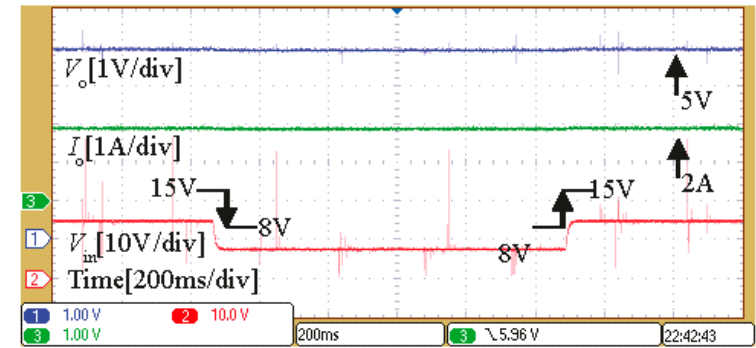

(d) HOSM+STD

Figure 7. Experimental results of output voltage for buck converter under step input voltage perturbation $\left(V_{\text {in }}=15 \mathrm{~V} \rightarrow 8 \mathrm{~V} \rightarrow 15 \mathrm{~V}, R=2.5 \Omega\right.$ ) with different controllers: Blue Channel 1 (top line) output voltage $V_{\mathrm{o}}(1 \mathrm{~V} / \mathrm{div})$, Green Channel 3 (middle line) load current $I$ o (1 A/div), Red Channel 2 (bottom line) input voltage $V$ in $(10 \mathrm{~V} / \mathrm{div})$.

As it can be seen from the figure, all four controllers show robustness to the input voltage perturbations. However, the voltage drop observed in SMC is bigger (about $120 \mathrm{mV}$ ), when compared with PI, HOSM and HOSM + STD. It is easy to indicate that the HOSM and HOSM + STD have 
better transient performance than PI controller, the overshoot and undershoot is almost negligible. The comparative analysis results between PI and HOSM + STD are shown in Table 6.

Table 6. Disturbance analysis results.

\begin{tabular}{cccc}
\hline \multirow{2}{*}{ Type } & \multirow{2}{*}{ Controller } & \multicolumn{2}{c}{ Output Voltage } \\
\cline { 3 - 4 } & & Voltage Drop/Raise & Recovery Time \\
\hline \multirow{2}{*}{$15 \mathrm{~V} \rightarrow 8 \mathrm{~V} \rightarrow 15 \mathrm{~V}$} & PI & $240 \mathrm{mV}$ & $42 \mathrm{~ms}$ \\
& HOSM + STD & $24 \mathrm{mV}$ & $10 \mathrm{~ms}$ \\
\hline \multirow{2}{*}{$10 \Omega \rightarrow 2.5 \Omega \rightarrow 10 \Omega$} & PI & $360 \mathrm{mV}$ & $12.5 \mathrm{~ms}$ \\
& HOSM + STD & $40 \mathrm{mV}$ & $2.5 \mathrm{~ms}$ \\
\hline
\end{tabular}

Finally, in order to test the robustness of the proposed controller against the output load resistance disturbances, the load resistance is changed from 10 to $2.5 \Omega$ and returns to $10 \Omega$. The load disturbance is realized by using an electronic load in Figure 5. The corresponding experimental results are presented in Figure 8.

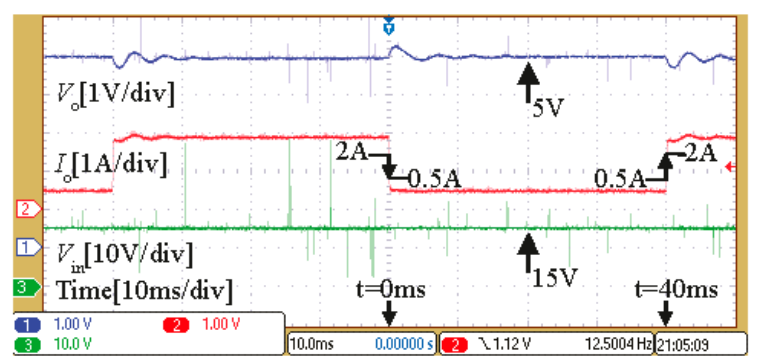

(a) PI

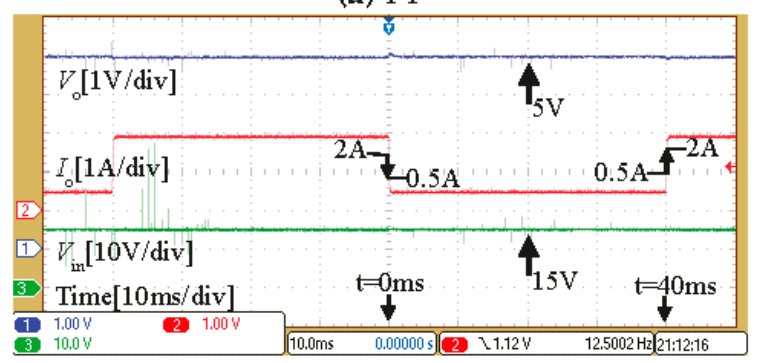

(c) HOSM

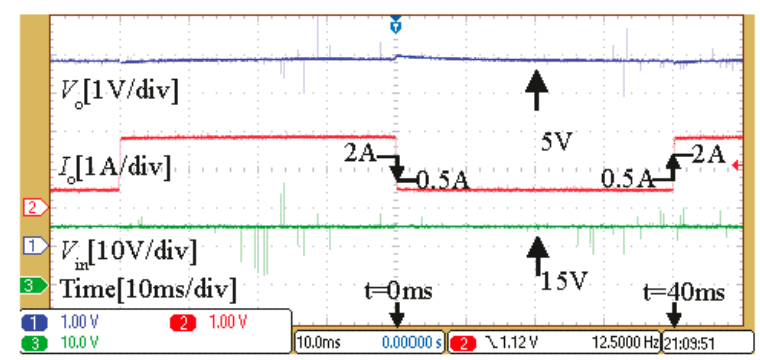

(b) SMC

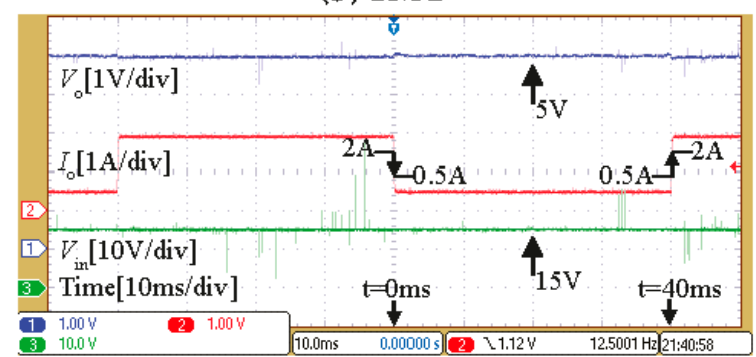

(d) HOSM+STD

Figure 8. Experimental results of output voltage for buck converter under step load resistance disturbance $\left(R=2.5 \Omega \rightarrow 10 \Omega\right.$ at $t=0 \mathrm{~ms}$ and $R=10 \Omega \rightarrow 2.5 \Omega$ at $\left.t=40 \mathrm{~ms}, V_{\text {in }}=15 \mathrm{~V}\right)$ with different controllers: Blue Channel 1 (top line) output voltage $V_{\mathrm{o}}(1 \mathrm{~V} / \mathrm{div})$, Red Channel 2 (middle line) load current Io (1 A/div), Green Channel 3 (bottom line) input voltage $V$ in $(10 \mathrm{~V} / \mathrm{div})$.

Similarly to the simulation results in Figure $4 a, b$, all four controllers show robustness to the load resistance disturbances. However, the PI controller has limited transient performance, such as the longer recovery time and larger overshoot/undershoot. The comparative analysis results between PI and HOSM + STD are shown in Table 6.

\section{Conclusions}

In this paper, two advanced nonlinear controllers (HOSM and HOSM + STD) feature high accuracy and strong robustness to input voltage perturbations and load disturbances for DC-DC buck converters in wireless power transfer systems are presented. According to the simulation and experimental results, it can be concluded that: 
1. The proposed HOSM controller can achieve stronger robustness, less steady state error, faster convergence, better voltage regulation and load regulation than SMC.

2. By adding a super-twisting differentiator (STD) into the HOSM controller design, the current sensor is no longer needed for the converter control. The proposed HOSM + STD controller only uses the measurement of output voltage as control input. The performance of HOSM + STD controller in terms of robustness, steady state error, voltage regulation is similar to HOSM controller.

Moreover, the two controllers (HOSM and HOSM + STD) can be further developed into a current sensor fault tolerant control to improve the reliability and availability of DC-DC buck converters. When the current sensor in Figure $1 \mathrm{~b}$ goes wrong, the capacitor current signal can be reconstructed by STD, thus the control law switches from HOSM to HOSM + STD. In this way, the continuous operation of buck converter under current sensor fault can be realized, and the robustness against input voltage perturbation and load resistance disturbance is also preserved. The presented novel control method in this paper for DC/DC power converter can thus be efficiently used in the DC power conversion stage for advanced wireless power transfer systems with the advantages of reduced number of components (sensors) and improved control robustness.

Acknowledgments: This work was supported by the Aeronautical Science Foundation of China under Grant 2014ZC53037 and the Seed Foundation of Innovation and Creation for Graduate Students in Northwestern Polytechnical University under Grant Z2016144 and the Key Science and Technology Program of Shaanxi Province, China under Grant 2016GY-149.

Author Contributions: All authors have worked on this manuscript together and all authors have read and approved this manuscript.

Conflicts of Interest: The authors declare no conflict of interest.

\section{References}

1. Kurs, A.; Karalis, A.; Moffatt, R.; Joannopoulos, J.D.; Fisher, P.; Soljačić, M. Wireless power transfer via strongly coupled magnetic resonances. Science 2007, 317, 83-86. [CrossRef] [PubMed]

2. Lu, X.; Niyato, D.; Wang, P.; Kim, D.I.; Han, Z. Wireless charger networking for mobile devices: Fundamentals, standards, and applications. IEEE Wirel. Commun. 2015, 22, 126-135. [CrossRef]

3. Olvitz, L.; Vinko, D.; Švedek, T. Wireless power transfer for mobile phone charging device. In Proceedings of the 35th International Convention on Information and Communication Technology, Electronics and Microelectronics (MIPRO), Opatija, Croatia, 21-25 May 2012; pp. 141-145.

4. Musavi, F.; Edington, M.; Eberle, W. Wireless power transfer: A survey of EV battery charging technologies. In Proceedings of the 4th Annual IEEE Energy Conversion Congress and Exposition (ECCE), Raleigh, NC, USA, 15-20 September 2012; pp. 1804-1810.

5. Zhang, F.; Liu, X.; Hackworth, S.A.; Sclabassi, R.J.; Sun, M. In vitro and in vivo studies on wireless powering of medical sensors and implantable devices. In Proceedings of the 2009 IEEE Life Science Systems and Applications Workshop, Bethesda, MD, USA, 9-10 April 2009; pp. 84-87.

6. Wang, J.; Li, J.; Ho, S.; Fu, W.; Li, Y.; Yu, H.; Sun, M. Lateral and angular misalignments analysis of a new PCB circular spiral resonant wireless charger. IEEE Trans. Magn. 2012, 48, 4522-4525. [CrossRef]

7. Prasad, P.; Thakur, N. Wireless resonant power transmission. In Proceedings of the International Conference on ICT for Sustainable Development (ICT4SD), Ahmedabad, India, 3-4 July 2015; pp. 417-425.

8. Ottman, G.K.; Hofmann, H.F.; Bhatt, A.C.; Lesieutre, G.A. Adaptive piezoelectric energy harvesting circuit for wireless remote power supply. IEEE Trans. Power Electron. 2002, 17, 669-676. [CrossRef]

9. Villa, J.L.; Sallán, J.; Llombart, A.; Sanz, J.F. Design of a high frequency inductively coupled power transfer system for electric vehicle battery charge. Appl. Energy 2009, 86, 355-363. [CrossRef]

10. Vadim, I.U. Survey paper variable structure systems with sliding modes. IEEE Trans. Autom. Control 1977, $22,212-222$.

11. Venkataramanan, R. Sliding Mode Control of Power Converters. Ph.D. Thesis, California Institute of Technology, Pasadena, CA, USA, 6 May 1986.

12. Utkin, V. Sliding mode control of DC/DC converters. J. Frankl. Inst. 2013, 350, 2146-2165. [CrossRef] 
13. Tan, S.-C.; Lai, Y.-M.; Cheung, M.K.-H.; Tse, C.K. On the practical design of a sliding mode voltage controlled buck converter. IEEE Trans. Power Electron. 2005, 20, 425-437. [CrossRef]

14. Tan, S.-C.; Lai, Y.; Tse, C.K. A unified approach to the design of PWM-based sliding-mode voltage controllers for basic DC-DC converters in continuous conduction mode. IEEE Trans. Circuits Syst. Regul. 2006, 53, 1816-1827.

15. Tan, S.-C.; Lai, Y.-M.; Tse, C.K. General design issues of sliding-mode controllers in DC-DC converters. IEEE Trans. Ind. Electron. 2008, 55, 1160-1174.

16. Wai, R.-J.; Shih, L.-C. Design of voltage tracking control for DC-DC boost converter via total sliding-mode technique. IEEE Trans. Ind. Electron. 2011, 58, 2502-2511. [CrossRef]

17. Chen, Z. PI and sliding mode control of a Cuk converter. IEEE Trans. Power Electron. 2012, 27, 3695-3703. [CrossRef]

18. Mamarelis, E.; Petrone, G.; Spagnuolo, G. Design of a sliding-mode-controlled SEPIC for PV MPPT applications. IEEE Trans. Ind. Electron. 2014, 61, 3387-3398. [CrossRef]

19. Lopez Santos, O.; Martinez-Salamero, L.; Garcia, G.; Valderrama-Blavi, H.; Sierra-Polanco, T. Robust sliding-mode control design for a voltage regulated quadratic boost converter. IEEE Trans. Power Electron. 2015, 30, 2313-2327. [CrossRef]

20. Oucheriah, S.; Guo, L. PWM-based adaptive sliding-mode control for boost DC-DC converters. IEEE Trans. Ind. Electron. 2013, 60, 3291-3294. [CrossRef]

21. Cavallo, A.; Guida, B. Sliding mode control for DC/DC converters. In Proceedings of the 51st IEEE Conference on Decision and Control (CDC), Maui, HI, USA, 10-13 December 2012; pp. 7088-7094.

22. Agostinelli, M.; Priewasser, R.; Marsili, S.; Huemer, M. Fixed-frequency Pseudo Sliding Mode control for a Buck-Boost DC-DC converter in mobile applications: A comparison with a linear PID controller. In Proceedings of the 2011 IEEE International Symposium of Circuits and Systems (ISCAS), Rio de Janeiro, Brazil, 15-18 May 2011; pp. 1604-1607.

23. Ahmed, M.; Kuisma, M.; Tolsa, K.; Silventoinen, P. Implementing sliding mode control for buck converter. In Proceeding of the 34th IEEE Power Electronics Specialist Conference (PESC), Acapulco, Mexico, 15-19 June 2003; Volume 2, pp. 634-637.

24. Lin, S.-C.; Tsai, C.-C. Adaptive voltage regulation of PWM buck DC-DC converters using backstepping sliding mode control. In Proceedings of the 2004 IEEE International Conference on Control Applications, Taipei, Taiwan, 2-4 September 2004; Volume 2, pp. 1382-1387.

25. Levant, A. Sliding order and sliding accuracy in sliding mode control. Int. J. Control 1993, 58, 1247-1263. [CrossRef]

26. Levant, A. Higher-order sliding modes, differentiation and output-feedback control. Int. J. Control 2003, 76, 924-941. [CrossRef]

27. Sahraoui, H.; Drid, S.; Chrifi-Alaoui, L.; Hamzaoui, M. Voltage control of DC-DC buck converter using second order sliding mode control. In Proceedings of the 3rd International Conference on Control, Engineering \& Information Technology (CEIT), Tlemcen, Algeria, 25-27 May 2015; pp. 1-5.

28. Huangfu, Y.; Wu, Y. A robust flyback converter based on high order sliding mode control for fuel cell. In Proceedings of the 40th Annual Conference of the IEEE Industrial Electronics Society (IECON), Dallas, TX, USA, 29 October-1 November 2014; pp. 3936-3940.

29. Shtessel, Y.; Edwards, C.; Fridman, L.; Levant, A. Sliding Mode Control and Observation; Springer: New York, NY, USA, 2014.

30. Levant, A. Principles of 2-sliding mode design. Automatica 2007, 43, 576-586. [CrossRef]

31. Komurcugil, H. Adaptive terminal sliding-mode control strategy for DC-DC buck converters. ISA Trans. 2012, 51, 673-681. [CrossRef] [PubMed]

32. Komurcugil, H. Non-singular terminal sliding-mode control of DC-DC buck converters. Control Eng. Pract. 2013, 21, 321-332. [CrossRef]

33. Liu, J.; Laghrouche, S.; Harmouche, M.; Wack, M. Adaptive-gain second-order sliding mode observer design for switching power converters. Control Eng. Pract. 2014, 30, 124-131. [CrossRef]

34. Levant, A. Robust exact differentiation via sliding mode technique. Automatica 1998, 34, 379-384. [CrossRef]

35. Davila, J.; Fridman, L.; Levant, A. Second-order sliding-mode observer for mechanical systems. IEEE Trans. Autom. Control 2005, 50, 1785-1789. [CrossRef] 
36. Zhang, C.; Wang, J.; Li, S.; Wu, B.; Qian, C. Robust control for PWM-based DC-DC buck power converters with uncertainty via sampled-data output feedback. IEEE Trans. Power Electron. 2015, 30, 504-515. [CrossRef]

37. Wang, J.; Li, S.; Yang, J.; Wu, B.; Li, Q. Extended state observer-based sliding mode control for PWM-based DC-DC buck power converter systems with mismatched disturbances. IET Control Theory Appl. 2015, 9, 579-586. [CrossRef]

38. Seshagiri, S.; Block, E.; Larrea, I.; Soares, L. Optimal PID design for voltage mode control of DC-DC buck converters. In Proceedings of the IEEE Indian Control Conference (ICC), Hyderabad, India, 4-6 January 2016; pp. 99-104.

39. Zhuo, S.; Huangfu, Y. Robust buck converter design with a high-order sliding mode differentiator. In Proceedings of the 41st Annual Conference of the IEEE Industrial Electronics Society (IECON), Yokohama, Japan, 9-12 November 2015; pp. 162-167.

40. Atassi, A.; Khalil, H. Separation results for the stabilization of nonlinear systems using different high-gain observer designs. Syst. Control Lett. 2000, 39, 183-191. [CrossRef]

41. Raviraj, V.; Sen, P.C. Comparative study of proportional-integral, sliding mode, and fuzzy logic controllers for power converters. IEEE Trans. Ind. Appl. 1997, 33, 518-524. [CrossRef]

42. Tan, S.-C.; Lai, Y.; Tse, C.K. Indirect sliding mode control of power converters via double integral sliding surface. IEEE Trans. Power Electron. 2008, 23, 600-611.

(C) 2016 by the authors; licensee MDPI, Basel, Switzerland. This article is an open access article distributed under the terms and conditions of the Creative Commons Attribution (CC-BY) license (http:/ / creativecommons.org/licenses/by/4.0/). 